\title{
Serial Optical Coherence Tomography at Baseline, 7 Days, and 1, 3, 6 and 12 Months After Bioresorbable Scaffold Implantation in a Growing Porcine Model
}

Taku Asano, MD; Jarkko Hytönen, MD; Ply Chichareon, MD; Jouni Taavitsainen, MD; Norihiro Kogame, MD; Yuki Katagiri, MD; Yosuke Miyazaki, MD, PhD; Kuniaki Takahashi, MD;

Rodrigo Modolo, MD; Hidenori Komiyama, MD; Erhan Tenekecioglu, MD;

Yohei Sotomi, MD, PhD; Joanna J. Wykrzykowska, MD, PhD; Jan J. Piek, MD, PhD;

John Martin, MD; Andreas Baumbach, MD; Anthony Mathur, MD;

Yoshinobu Onuma, MD, PhD; Seppo Ylä-Herttuala, MD, PhD; Patrick W. Serruys, MD, PhD

\begin{abstract}
Background: Little is known about serial changes in lumen and device dimensions after bioresorbable scaffold implantation in a growing animal model.

Methods and Results: ABSORB ( $n=14)$ or bare metal stents (ICROS amg [Abbott Vascular, Santa Clara, CA, USA], Winsen-Luhe, Germany; $n=15$ ) were implanted in the coronary arteries of domestic swine (a hybrid of Finnish-Norwegian Landrace swine) weighing 30-35 kg. Angiography and optical coherence tomography (OCT) were performed immediately after implantation and repeated at 7 days, 1, 3, 6 and 12 months after the index procedure. One month after implantation, mean lumen area decreased relative to baseline in both groups (relative area change from baseline, $-41.4 \pm 15.6 \%$ for ABSORB vs. $-20.9 \pm 18.6 \%$ for ICROS) while mean device area decreased only in the ABSORB group (relative area change: $-11.1 \pm 9.4 \%$ vs. $+0.14 \pm 7.95 \%$, respectively). At 12 months, mean lumen area increased relative to baseline in both groups (relative area change from baseline, $+55.6 \pm 22.4 \%$ vs. $+32.3 \pm 83.6 \%$, respectively) in accordance with the swine growth weighing up to $260-300 \mathrm{~kg}$. Mean device area in the ICROS group remained stable whereas that in the ABSORB group began to increase between 3 and 6 months along with the vessel growth (relative area change: $+107.8 \pm 25.7 \%$ vs. $+0.14 \pm 7.95 \%)$.
\end{abstract}

Conclusions: In the growing porcine model, ABSORB was associated with greater extent of recoil 1 month after implantation compared with ICROS but demonstrated substantial adaptability to vessel growth in late phase.

Key Words: Coronary artery disease; Pediatrics; Percutaneous coronary intervention; Stent

B ioresorbable scaffolds (BRS) have been developed to reduce potential long-term issues related to permanent caging with metallic material with or without a durable polymer. BRS have been designed to be fully resorbed, after they have fulfilled their important role of scaffolding to prevent vessel recoil and constrictive remodeling, which are observed up to 6 months after revascularization. ${ }^{1,2}$ During the scaffold degradation process, vessels treated with BRS potentially undergo restoration of pul- satility, cyclic strain, physiological shear stress, mechanotransduction, conformability and growth capability, which are all hindered by metallic caging. ${ }^{36}$

An everolimus-eluting bioresorbable vascular scaffold (ABSORB BVS, Abbott Vascular, Santa Clara, CA, USA) has a semicrystalline poly-L-lactic acid (PLLA) backbone coated by a thin amorphous layer of poly-D,L-lactic acid containing everolimus. This first generation of BRS has undergone intense investigation with regard to bench test-

Received August 21, 2018; revised manuscript received November 5, 2018; accepted November 26, 2018; J-STAGE Advance Publication released online January 31, 2019 Time for primary review: 23 days

Department of Cardiology, Academic Medical Center, University of Amsterdam, Amsterdam (T.A., P.C., N.K., Y.K., K.T., R.M., H.K., Y.S., J.J.W., J.J.P.), the Netherlands; Department of Cardiology, St. Luke's International Hospital, Tokyo (T.A.), Japan; A.I. Virtanen Institute for Molecular Sciences, University of Eastern Finland, Kuopio (J.H., J.T., S.Y.-H.), Finland; ThoraxCenter, Erasmus Medical Center, Rotterdam (Y.M., E.T., Y.O.), the Netherlands; Division of Medicine, University College London, London (J.M.); Department of Cardiology, Barts Health NHS Trust, London (A.B., A.M.); Department of Cardiology, Queen Mary University of London, London (A.B., A.M.), UK; Cardialysis, Rotterdam (Y.O.), the Netherlands; and National Heart and Lung Institute, Imperial College London, London (P.W.S.), UK

The first two author contributed equally to this work (T.A., J.H.).

Mailing address: Yoshinobu Onuma, MD, PhD, Westblaak 98, 3012 KM Rotterdam, the Netherlands. E-mail: yoshinobuonuma@ gmail.com

ISSN-1346-9843 All rights are reserved to the Japanese Circulation Society. For permissions, please e-mail: cj@j-circ.or.jp 


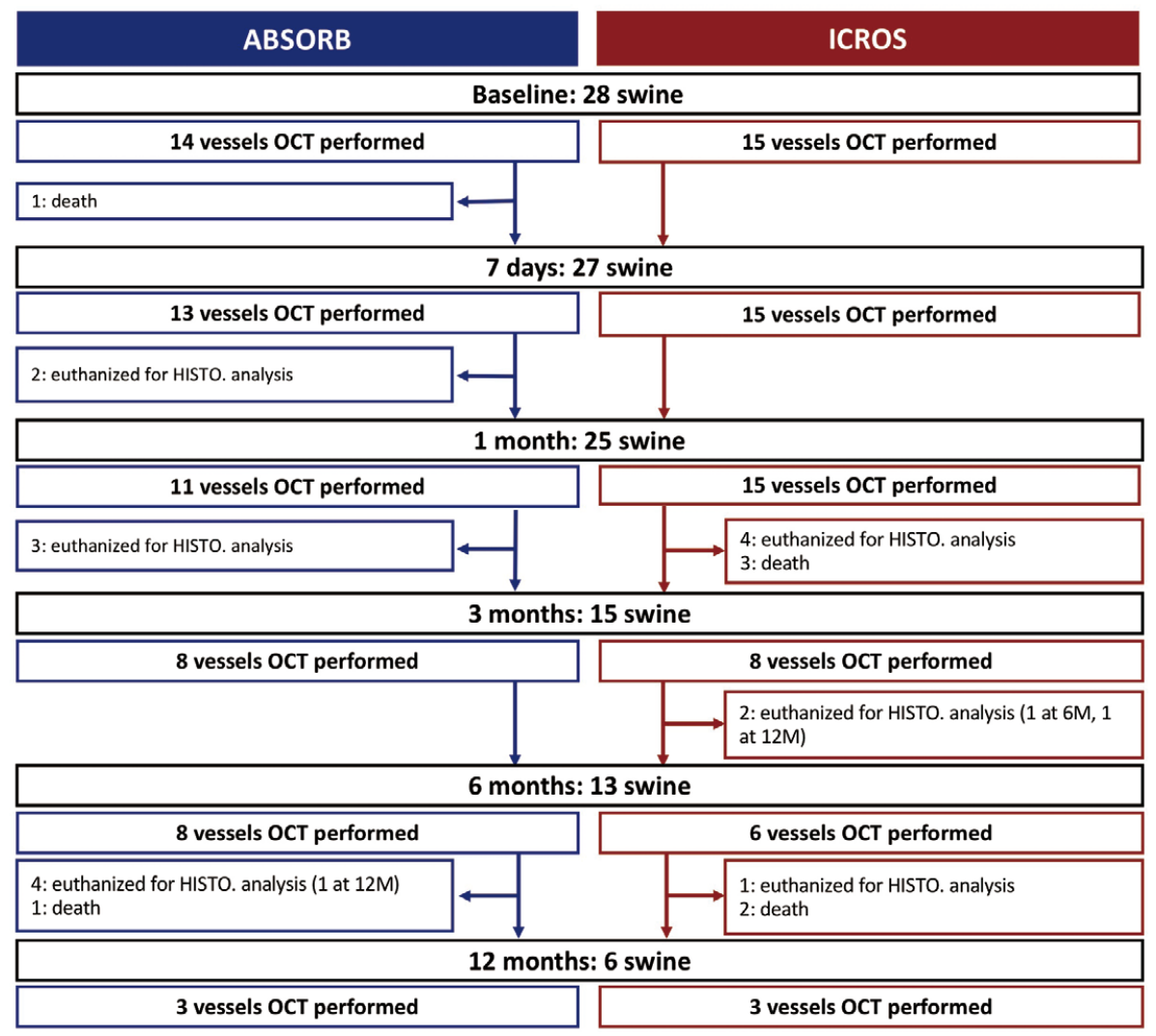

Figure 1. Study flow chart. HISTO, histological; OCT, optical coherence tomography. M, months.

ing, preclinical and clinical studies. ${ }^{7-9}$ Several long-term reports on this device, however, raised concerns about safety endpoints (very late scaffold thrombosis), when compared with the conventional metallic stent. ${ }^{9-11}$ Based on these results, the sale of the device was discontinued in September 2017. Nevertheless, the device still constitutes a benchmark for the development of next-generation BRS.

Ormiston et al observed significant in vitro structural recoil of ABSORB scaffolds $1 \mathrm{~h}$ after deployment. ${ }^{12}$ Nakatani et al reported luminal enlargement after ABSORB scaffold implantation between 3 and 24 months on nonserial optical coherence tomography (OCT) using a Yucatan mini-swine model but did not report data during the first 60 days. $^{8}$ To the best of our knowledge, there are no public-domain data with regard to the serial changes in lumen, scaffold and neointimal area between implantation and 12 months after ABSORB implantation, including 1-month observation, in a growing porcine model. The aim of the present study was therefore to assess the serial changes in luminal and device dimensions after implantation of the ABSORB scaffold compared with a metallic stent using serial OCT assessments up to 12 months (baseline, 7 days, 1 month, 3 months, 6 months and 12 months) in a growing porcine model, especially focusing on the early phase $(0-30$ days) of mechanical integrity and the late phase (30-360 days) of scaffold adaptability to the vessel luminal enlargement in accordance with animal growth.

\section{Methods}

Experimental Model

All animal experiments were approved by the National Animal Experiment Board and conform to National Institutes of Health guidelines. Domestic pigs (a hybrid of Finnish-Norwegian Landrace swine) weighing $30-35 \mathrm{~kg}$ $(\mathrm{n}=28)$ were used in the study. After atropine $(0.05 \mathrm{mg} / \mathrm{kg}$ i.m., Leiras, Helsinki, Finland), animals were sedated with azaperone $(8 \mathrm{mg} / \mathrm{kg}$ i.m., Stresnil, Jansen, Titusville, NJ, USA) prior to anesthesia with propofol $(15 \mathrm{mg} / \mathrm{kg} / \mathrm{h}$ i.v., Propofol-Lipuro, Braun Medical, Melsungen, Germany). The animals were intubated and mechanically ventilated. Fentanyl (10 $\mu \mathrm{g} / \mathrm{kg} / \mathrm{h}$ i.v., Janssen), buprenorphine (0.3 mg i.m., Temgesic, BR Pharmaceuticals, Leeds, UK) and carprofen (4mg/kg i.m. Rimadyl, Pfizer, New York, NY, USA) were used as analgesics. The animals received $100 \mathrm{mg}$ aspirin (ASA Ratiopharm, Ratiopharm, Ulm, Germany) and $2.5 \mathrm{mg}$ bisoprolol (Bisoprolol Orion, Orion, Espoo, Finland) starting 3 days before scaffold implantation until the end of the experiment. Clopidogrel (Plavix, Sanofi, Gentilly, France) was used with a loading dose of $150 \mathrm{mg}$ before scaffold implantation and a dose of $75 \mathrm{mg}$ daily until the end of the experiment. The animals received $30 \mathrm{mg}$ enoxaparine (Klexane, Sanofi, Gentilly, France) daily after scaffold implantation to prevent scaffold thrombosis caused by the comparatively active coagulation system of the pigs. Enoxaparine was given i.v. before catheterization proce- 


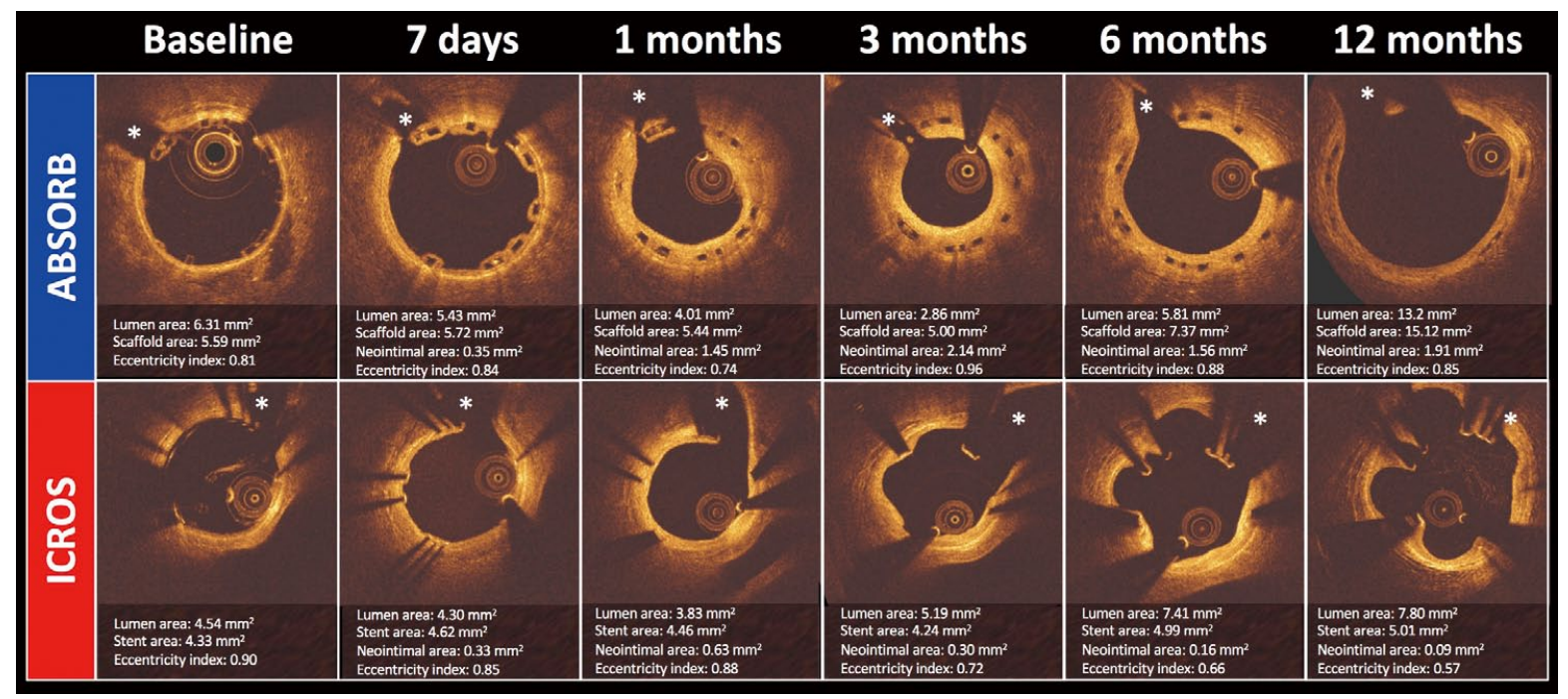

Figure 2. Representative serial optical coherence tomography (OCT) of the ABSORB bioresorbable scaffold and ICROS bare metal stent. *Side branch.

\begin{tabular}{|lccc|}
\hline Table 1. Lesion and Procedure Characteristics & ABSORB & & P-value \\
Vessel & $(\mathbf{n = 1 4 )}$ & $\begin{array}{c}\text { ICROS } \\
(\mathbf{n = 1 5})\end{array}$ & 0.002 \\
LAD & $2(14.3)$ & $7(46.7)$ & \\
LCX & $6(42.9)$ & $5(33.3)$ & \\
RCA & $6(42.9)$ & $3(20)$ & \\
Procedure & & & NA \\
Pre-dilatation & $0(0)$ & $0(0)$ & \\
Device implantation & & & 0.051 \\
Nominal device diameter (mm) & $2.86 \pm 0.23$ & $2.75 \pm 0.0$ & 1.000 \\
Device length (mm) & $18.0 \pm 0.0$ & $18.0 \pm 0.0$ & 0.057 \\
Maximum inflation pressure (atm) & $9.64 \pm 2.73$ & $12.07 \pm 3.31$ & 0.005 \\
Post-dilatation & $11(78.6)$ & $4(26.7)$ & 0.661 \\
Nominal balloon diameter (mm) & $3.05 \pm 0.35$ & $3.13 \pm 0.14$ & 1.000 \\
Balloon length (mm) & $15.0 \pm 0.0$ & $15.0 \pm 0.0$ & 0.343 \\
Maximum inflation pressure (atm) & $12.82 \pm 5.17$ & $15.75 \pm 2.87$ & \\
\hline
\end{tabular}

Data given as $\mathrm{n}(\%)$ or mean $\pm \mathrm{SD}$. LAD, left anterior descending artery; LCX, left circumflex artery; RCA, right coronary artery.

dures (30 mg i.v.).

Animals were catheterized via the right femoral artery with a 6-F introducer sheath (Cordis, Bridgewater, NJ, USA) using the standard Seldinger technique. Angiography was performed using a GE Innova 3100IQ system (GE Healthcare, Waukesha, WI, USA). Amplatz-type guiding catheters were used to access and image the coronary arteries (left anterior descending artery [LAD], left circumflex artery $[\mathrm{LCX}]$ and right coronary artery [RCA]). Animals received 1 ABSORB BVS 1.1. or bare metal stent (BMS; ICROS, amg, Winsen-Luhe, Germany) either in the LAD, LCX or RCA. ABSORB scaffolds and ICROS stents were implanted in normal (non-atherosclerotic) vessels according to instructions to accommodate a device to artery ratio of 1.1:1. The target vessels underwent OCT immediately after device implantation. OCT was performed using a C7-XR intravascular imaging system and Dragonfly catheter (St. Jude Medical, St. Paul, MN, USA) with a pullback speed of $20 \mathrm{~mm} / \mathrm{s}$. Angiography and OCT were repeated 7 days, 1 month, 3 months, 6 months and 12 months after the index procedure.

\section{Quantitative Coronary Angiography (QCA)}

QCA was performed using a GE Advanced Workstation by an experienced blinded analyzer (J.H.). Measurements of minimum lumen diameter (MLD), reference lumen diameter, diameter stenosis (DS) and late lumen loss (LLL) at each time point (before, after the procedure, 7 days, 1 , 3, 6, 12 months after implantation) were made. Reference lumen diameter was measured as mean lumen diameter at 
$5 \mathrm{~mm}$ proximal to the device segment. LLL was calculated as the difference in minimum lumen diameter between post-procedure and follow-up assessments. MLD, DS and LLL were measured on in-scaffold/stent analysis.

\section{OCT}

For OCT, quantitative measurements were performed across device segments and peri-device segments $(\leq 5 \mathrm{~mm}$ proximal and distal to the device edge) at 1-mm intervals according to previously published methods. ${ }^{13}$ Parameters were measured using QCU-CMS version 4.69 (Leiden University Medical Center, Leiden, The Netherlands) by 2 experienced observers (T.A. and P.C.): mean and minimum lumen area, mean and minimum device area, neointimal area and device expansion index.8,14 Device and neointimal area were measured based on endoluminal scaffold/stent contour. The circularity of the lumen was evaluated using the eccentricity index, calculated as the ratio of minimum and the maximum lumen diameter per crosssection. ${ }^{15}$ The longitudinal variance in lumen diameter was assessed using the asymmetry index $(1-$ minimum lumen diameter/maximum lumen diameter).$^{15}$ Neointimal volume obstruction was calculated as mean endoluminal neointimal volume divided by mean endoluminal scaffold/stent volume.

\section{Histology}

The coronary arteries were harvested after perfusion fixation of the hearts with $1 \%$ paraformaldehyde and further fixed in $4 \%$ paraformaldehyde at $4{ }^{\circ} \mathrm{C}$ overnight, which were subsequently dehydrated and processed into methacrylatebased mold and sectioned for histology. Histological sections were stained with hematoxylin and eosin. Morphological measurements were performed for the cross-sectional area of external elastic lamina (EEL), internal elastic lamina (IEL), lumen, neointimal thickness and percent stenosis. The percent stenosis was calculated as (1-[lumen area/IEL area]) $\times 100$. Neointimal thickness was defined as the distance from the inner surface of each strut to the luminal border. The degrees of vessel injury and neointimal inflammation were scored in accordance with the methods previously reported.16

\section{Statistical Analysis}

Data are expressed as mean \pm SD or median (IQR). Group means for continuous variables with normal and nonnormal distributions were compared using Student's t-test and Mann-Whitney U-test, respectively. Categorical variables were compared using the Pearson's chi-squared test or Fischer's exact test, as appropriate. Paired Student's t-test or Wilcoxon signed rank test was applied for paired serial comparisons of OCT parameters (e.g., at baseline vs. at 1 month), as appropriate. On serial OCT analysis, a mixed-effects model (random intercept and slope) liner regression analysis was performed to assess the difference in the rate of change (slope) in each parameter between the ABSORB and ICROS group. ${ }^{17}$ In this mixed-model analysis, the repeated observations were clustered within a subject. Statistical significance was assumed at $\mathrm{P}<0.05$. All statistical analysis was performed with SPSS version 24.0.0 (IBM, New York, NY, USA).

\section{Results}

Twenty-eight swine with 29 vessels (14 vessels in the
ABSORB group, 15 vessels in the ICROS group) were investigated on OCT analysis. Histological analysis was performed in 25 swine with 27 vessels (17 vessels in the ABSORB group, 10 vessels in the ICROS group), including 7 swine dedicated for histological analysis without OCT analysis. The flow chart of the current OCT study is presented in Figure 1. During the study period, 2 swine died during the procedure and 19 swine were killed for the pathology analysis (Figure 1). During the course of the experiment (12 months), the swine grew from $30.4 \mathrm{~kg}$ median weight (IQR, 33.2-36.6 kg) to $270 \mathrm{~kg}$ median weight (IQR, 267-270 kg; Figure 2).

\section{Anatomical Site and Procedural Characteristics}

The details of the anatomical site for device deployment are reported in Table 1. No balloon dilatations were performed prior to device implantation. Mean nominal device diameter was numerically higher in the ABSORB groups $(2.86 \pm 0.23 \mathrm{~mm}$ for ABSORB and $2.75 \pm 0.00 \mathrm{~mm}$ for ICROS, $\mathrm{P}=0.051)$. Post-balloon dilatation was performed after 11 implantations $(78.6 \%)$ in the ABSORB group whereas 4 implantations (26.7\%) were followed by post-balloon dilatation in the ICROS group $(\mathrm{P}=0.005$; Table 1$)$.

\section{QCA}

The results of QCA are summarized in Supplementary Table 1. Post-procedural MLD was similar between the 2 groups (ABSORB, $2.60 \pm 0.36 \mathrm{~mm}$ vs. ICROS, $2.52 \pm 0.24 \mathrm{~mm}$; $\mathrm{P}=0.400$ ). At 1-month follow-up, MLD in the ABSORB group was significantly lower than in the ICROS group $(1.78 \pm 0.40 \mathrm{~mm}$ vs. $2.32 \pm 0.28 \mathrm{~mm}, \mathrm{P}=0.001)$. DS and LLL were significantly higher in the ABSORB group 1 month after the index procedure (DS, $38.3 \pm 11.7 \%$ vs. $13.5 \pm 7.9 \%$, $\mathrm{P}<0.001$; LLL, $0.75 \pm 0.36 \mathrm{~mm}$ vs. $0.20 \pm 0.24 \mathrm{~mm}, \mathrm{P}<0.001$ ). After 1-month follow-up, in the ABSORB group, MLD increased and reached $3.63 \pm 0.40 \mathrm{~mm}$ at the 12 -month follow-up whereas MLD remained stable in the ICROS $\operatorname{arm}(2.23 \pm 0.49 \mathrm{~mm}$ at 12 -month follow-up).

\section{OCT}

Representative serial OCT assessment in both groups is presented in Figure 2. At 12 months, strut boxes of ABSORB were still clearly observed using OCT. The results of serial OCT are presented with body weight in Table 2, Figure 3. In proportion to the swine growth, reference lumen area increased in both groups over 12 months (baseline, $5.46 \pm 1.82$ for ABSORB vs. $5.52 \pm 0.82 \mathrm{~mm}^{2}$ for ICROS; 12 months, $10.78 \pm 1.68$ for ABSORB vs. $9.12 \pm 1.83 \mathrm{~mm}^{2}$ for ICROS; Figure 3A,3B).

In the ABSORB group, mean lumen area decreased at 1 month (baseline, $6.25 \pm 1.37 \mathrm{~mm}^{2} ; 1$ month, $3.80 \pm 1.47 \mathrm{~mm}^{2}$; relative change from baseline, $-41.4 \pm 15.6 \% ; \mathrm{P}=0.003$ ) and subsequently increased especially between 3 and 12 months (12 months, $9.24 \pm 3.01 \mathrm{~mm}^{2}$; relative change from baseline, $+55.6 \pm 22.4 \%$; $\mathrm{P}=0.109$; Figure 3C). In the ICROS group, lumen area decreased at 1 month (baseline, $5.79 \pm 0.91 \mathrm{~mm}^{2}$; 1 month, $4.53 \pm 1.18 \mathrm{~mm}^{2}$; relative change from baseline, $-20.9 \pm 18.6 \% ; \mathrm{P}=0.003)$ and later increased by 12 months (12 months, $6.76 \pm 3.85 \mathrm{~mm}^{2}$; relative change from baseline, $+32.3 \pm 83.6 \% ; \mathrm{P}=0.593$; Figure 3C). The mechanisms of lumen increase are fundamentally different: in the ABSORB group, a homogeneous concentric lumen increase was observed, whereas the increase in lumen area in the ICROS group was the result of evagination of the vessel wall between the struts, as observed in the representative case 


\begin{tabular}{|c|c|c|c|c|c|c|c|c|c|c|}
\hline & \multicolumn{2}{|c|}{ Baseline } & \multicolumn{2}{|r|}{7 days } & \multicolumn{2}{|r|}{$1 \mathrm{M}$} & \multicolumn{2}{|r|}{$3 \mathrm{M}$} & \multicolumn{2}{|r|}{$6 \mathrm{M}$} \\
\hline & $\mathbf{n}$ & Mean \pm SD & $\mathbf{n}$ & Mean \pm SD & $\mathbf{n}$ & Mean \pm SD & $\mathbf{n}$ & Mean \pm SD & $\mathbf{n}$ & Mean \pm SD \\
\hline \multicolumn{11}{|c|}{ Body weight (kg) } \\
\hline ABSORB & 14 & $31.59 \pm 3.55$ & 13 & $35.93 \pm 4.42$ & 11 & $53.02 \pm 18.35$ & 8 & $107.68 \pm 26.65$ & 8 & $168.25 \pm 41.81$ \\
\hline ICROS & 15 & $35.34 \pm 3.96$ & 15 & $38.82 \pm 4.20$ & 15 & $50.45 \pm 4.48$ & 8 & $106.73 \pm 11.11$ & 6 & $158.28 \pm 7.81$ \\
\hline P-value & & 0.016 & & 0.098 & & 0.54 & & 0.382 & & 0.414 \\
\hline \multicolumn{11}{|c|}{$\begin{array}{l}\text { Reference lumen } \\
\text { area }\left(\mathrm{mm}^{2}\right)\end{array}$} \\
\hline ABSORB & 14 & $5.46 \pm 1.84$ & 13 & $4.84 \pm 1.24$ & 11 & $5.58 \pm 2.10$ & 8 & $6.58 \pm 1.95$ & 8 & $7.93 \pm 1.89$ \\
\hline ICROS & 15 & $5.52 \pm 0.82$ & 15 & $5.09 \pm 0.70$ & 15 & $5.93 \pm 1.79$ & 8 & $7.22 \pm 1.43$ & 6 & $8.22 \pm 1.47$ \\
\hline P-value & & 0.847 & & 0.413 & & 0.443 & & 0.645 & & 0.852 \\
\hline \multicolumn{11}{|c|}{$\begin{array}{l}\text { Minimum lumen } \\
\text { area }\left(\mathrm{mm}^{2}\right)\end{array}$} \\
\hline ABSORB & 14 & $5.56 \pm 1.33$ & 13 & $4.59 \pm 1.00$ & 11 & $2.82 \pm 1.47$ & 8 & $3.16 \pm 0.99$ & 8 & $4.35 \pm 1.25$ \\
\hline ICROS & 15 & $5.11 \pm 0.80$ & 15 & $4.42 \pm 0.88$ & 15 & $3.68 \pm 1.20$ & 8 & $3.86 \pm 1.18$ & 6 & $4.85 \pm 1.93$ \\
\hline P-value & & 0.290 & & 0.717 & & 0.109 & & 0.234 & & 0.852 \\
\hline \multicolumn{11}{|l|}{$\begin{array}{l}\text { Mean lumen } \\
\text { area }\left(\mathrm{mm}^{2}\right)\end{array}$} \\
\hline ABSORB & 14 & $6.25 \pm 1.37$ & 13 & $5.33 \pm 1.05$ & 11 & $3.80 \pm 1.47$ & 8 & $3.63 \pm 1.00$ & 8 & $5.11 \pm 1.49$ \\
\hline ICROS & 15 & $5.79 \pm 0.91$ & 15 & $4.91 \pm 0.88$ & 15 & $4.53 \pm 1.18$ & 8 & $4.72 \pm 1.40$ & 6 & $6.27 \pm 2.39$ \\
\hline P-value & & 0.27 & & 0.274 & & 0.217 & & 0.083 & & 0.491 \\
\hline \multicolumn{11}{|c|}{$\begin{array}{l}\text { Minimum device } \\
\text { area }\left(\mathrm{mm}^{2}\right)\end{array}$} \\
\hline ABSORB & 14 & $5.22 \pm 1.15$ & 13 & $4.81 \pm 0.98$ & 11 & $4.74 \pm 1.13$ & 8 & $4.52 \pm 0.82$ & 8 & $5.70 \pm 1.27$ \\
\hline ICROS & 15 & $4.75 \pm 0.74$ & 15 & $4.55 \pm 0.98$ & 15 & $4.90 \pm 0.91$ & 8 & $4.68 \pm 0.89$ & 6 & $4.97 \pm 1.26$ \\
\hline P-value & & 0.172 & & 0.467 & & 0.646 & & 0.878 & & 0.491 \\
\hline \multicolumn{11}{|l|}{$\begin{array}{l}\text { Mean device } \\
\text { area }\left(\mathrm{mm}^{2}\right)\end{array}$} \\
\hline ABSORB & 14 & $5.81 \pm 1.25$ & 13 & $5.37 \pm 0.97$ & 11 & $5.26 \pm 1.21$ & 8 & $5.09 \pm 0.84$ & 8 & $6.63 \pm 1.61$ \\
\hline ICROS & 15 & $5.32 \pm 0.89$ & 15 & $5.03 \pm 0.96$ & 15 & $5.30 \pm 0.98$ & 8 & $5.15 \pm 1.02$ & 6 & $5.49 \pm 1.25$ \\
\hline P-value & & 0.234 & & 0.363 & & 0.878 & & 0.959 & & 0.345 \\
\hline \multicolumn{11}{|c|}{$\begin{array}{l}\text { Mean neointimal } \\
\text { thickness }(\mathrm{mm})\end{array}$} \\
\hline ABSORB & & & 13 & $0.03 \pm 0.01$ & 11 & $0.21 \pm 0.10$ & 8 & $0.20 \pm 0.08$ & 8 & $0.18 \pm 0.05$ \\
\hline ICROS & & & 15 & $0.03 \pm 0.02$ & 15 & $0.11 \pm 0.09$ & 8 & $0.10 \pm 0.15$ & 6 & $0.07 \pm 0.13$ \\
\hline P-value & & & & 0.170 & & 0.009 & & 0.028 & & 0.043 \\
\hline \multicolumn{11}{|c|}{$\begin{array}{l}\text { Mean neointimal } \\
\text { area }\left(\mathrm{mm}^{2}\right)\end{array}$} \\
\hline ABSORB & & & 13 & $0.28 \pm 0.06$ & 11 & $1.49 \pm 0.59$ & 8 & $1.46 \pm 0.55$ & 8 & $1.52 \pm 0.43$ \\
\hline ICROS & & & 15 & $0.23 \pm 0.14$ & 15 & $0.87 \pm 0.64$ & 8 & $0.76 \pm 1.01$ & 6 & $0.51 \pm 0.93$ \\
\hline P-value & & & & 0.156 & & 0.013 & & 0.028 & & 0.043 \\
\hline \multicolumn{11}{|c|}{$\begin{array}{l}\text { Neointimal } \\
\text { volume }\left(\mathrm{mm}^{3}\right)\end{array}$} \\
\hline ABSORB & & & 13 & $5.08 \pm 0.96$ & 11 & $25.53 \pm 10.15$ & 8 & $25.21 \pm 11.15$ & 8 & $27.74 \pm 7.53$ \\
\hline ICROS & & & 15 & $3.49 \pm 1.89$ & 15 & $13.42 \pm 9.52$ & 8 & $9.91 \pm 10.64$ & 6 & $10.67 \pm 21.98$ \\
\hline P-value & & & & 0.008 & & 0.004 & & 0.021 & & 0.043 \\
\hline \multicolumn{11}{|c|}{$\begin{array}{l}\text { Neointimal volume } \\
\text { obstruction (\%) }\end{array}$} \\
\hline ABSORB & & & 13 & $5.47 \pm 1.52$ & 11 & $30.05 \pm 14.08$ & 8 & $29.49 \pm 10.99$ & 8 & $23.87 \pm 8.34$ \\
\hline ICROS & & & 15 & $4.43 \pm 2.32$ & 15 & $16.53 \pm 11.85$ & 8 & $14.32 \pm 19.81$ & 6 & $9.82 \pm 18.28$ \\
\hline P-value & & & & 0.201 & & 0.015 & & 0.028 & & 0.043 \\
\hline
\end{tabular}

‡Difference in the rate of change (slope) (baseline-12 months) between ABSORB and ICROS. M, month(s).

(Table 2 continued the next page.)

(Figure 2). The serial change in lumen eccentricity index in the ICROS group reflected the evagination process (Supplementary Figure 1; Supplementary Table 2).

In the ABSORB group, mean device area decreased at 1 month (baseline, $5.81 \pm 1.25 \mathrm{~mm}^{2} ; 1$ month, $5.26 \pm 1.21 \mathrm{~mm}^{2}$; relative change from baseline, $-11.1 \pm 9.4 \% ; \mathrm{P}=0.006)$ and later increased especially between 3 and 12 months (12 months, $11.58 \pm 3.48 \mathrm{~mm}^{2}$; relative change from baseline, $+107.8 \pm 25.7 \% ; \quad P=0.109)$. Scaffold discontinuity was observed as early as 1 month after implantation in 1 vessel. In that case, relative change in scaffold area at 1 month was $-38.8 \%$. In contrast, in the ICROS group, mean device 


\begin{tabular}{|c|c|c|c|c|c|c|c|c|}
\hline & \multicolumn{2}{|r|}{$12 \mathrm{M}$} & \multirow[b]{2}{*}{ P-value $\ddagger$} & \multicolumn{5}{|c|}{ P-value for paired test } \\
\hline & $\mathbf{n}$ & Mean \pm SD & & $\begin{array}{l}\text { Baseline } \\
\text { vs. } 7 \text { days }\end{array}$ & $\begin{array}{l}\text { Baseline } \\
\text { vs. } 1 \mathrm{M}\end{array}$ & $\begin{array}{c}\text { Baseline } \\
\text { vs. } 3 \mathrm{M}\end{array}$ & $\begin{array}{c}\text { Baseline } \\
\text { vs. } 6 \mathrm{M}\end{array}$ & $\begin{array}{l}\text { Baseline } \\
\text { vs. } 12 \mathrm{M}\end{array}$ \\
\hline \multicolumn{9}{|c|}{ Body weight $(\mathrm{kg})$} \\
\hline ABSORB & 3 & $269 \pm 1.730$ & \multirow{3}{*}{0.988} & 0.001 & 0.003 & 0.012 & 0.012 & 0.109 \\
\hline ICROS & 3 & $280 \pm 17.32$ & & 0.001 & 0.001 & 0.012 & 0.028 & 0.109 \\
\hline P-value & & 0.400 & & & & & & \\
\hline \multicolumn{9}{|c|}{$\begin{array}{l}\text { Reference lumen } \\
\text { area }\left(\mathrm{mm}^{2}\right)\end{array}$} \\
\hline ABSORB & 3 & $10.78 \pm 1.68$ & \multirow{3}{*}{0.240} & 0.011 & 0.657 & 0.069 & 0.012 & 0.109 \\
\hline ICROS & 3 & $9.12 \pm 1.83$ & & 0.191 & 0.112 & 0.012 & 0.028 & 0.109 \\
\hline P-value & & 0.400 & & & & & & \\
\hline \multicolumn{9}{|c|}{$\begin{array}{l}\text { Minimum lumen } \\
\text { area }\left(\mathrm{mm}^{2}\right)\end{array}$} \\
\hline ABSORB & 3 & $8.01 \pm 2.48$ & \multirow{3}{*}{0.513} & 0.002 & 0.003 & 0.012 & 0.017 & 0.109 \\
\hline ICROS & 3 & $3.94 \pm 1.72$ & & 0.002 & 0.001 & 0.036 & 0.833 & 1.000 \\
\hline P-value & & 0.200 & & & & & & \\
\hline \multicolumn{9}{|l|}{$\begin{array}{l}\text { Mean lumen } \\
\text { area }\left(\mathrm{mm}^{2}\right)\end{array}$} \\
\hline ABSORB & 3 & $9.24 \pm 3.01$ & \multirow{3}{*}{0.285} & 0.002 & 0.003 & 0.012 & 0.017 & 0.109 \\
\hline ICROS & 3 & $6.76 \pm 3.85$ & & 0.001 & 0.003 & 0.050 & 0.600 & 0.593 \\
\hline P-value & & 0.400 & & & & & & \\
\hline \multicolumn{9}{|c|}{$\begin{array}{l}\text { Minimum device } \\
\text { area }\left(\mathrm{mm}^{2}\right)\end{array}$} \\
\hline ABSORB & 3 & $10.22 \pm 2.83$ & \multirow{3}{*}{0.006} & 0.011 & 0.008 & 0.050 & 0.036 & 0.109 \\
\hline ICROS & 3 & $4.57 \pm 0.12$ & & 0.112 & 0.156 & 0.263 & 0.345 & 0.593 \\
\hline P-value & & 0.100 & & & & & & \\
\hline \multicolumn{9}{|l|}{$\begin{array}{l}\text { Mean device } \\
\text { area }\left(\mathrm{mm}^{2}\right)\end{array}$} \\
\hline ABSORB & 3 & $11.58 \pm 3.48$ & \multirow{3}{*}{0.003} & 0.023 & 0.006 & 0.036 & 0.017 & 0.109 \\
\hline ICROS & 3 & $4.88 \pm 0.100$ & & 0.061 & 0.532 & 1.000 & 0.463 & 1.000 \\
\hline P-value & & 0.100 & & & & & & \\
\hline \multicolumn{9}{|c|}{$\begin{array}{l}\text { Mean neointimal } \\
\text { thickness }(\mathrm{mm})\end{array}$} \\
\hline ABSORB & 3 & $0.20 \pm 0.02$ & \multirow{3}{*}{0.121} & NA & NA & NA & NA & NA \\
\hline ICROS & 3 & $0.13 \pm 0.21$ & & NA & NA & NA & NA & NA \\
\hline P-value & & 0.700 & & & & & & \\
\hline \multicolumn{9}{|c|}{$\begin{array}{l}\text { Mean neointimal } \\
\text { area }\left(\mathrm{mm}^{2}\right)\end{array}$} \\
\hline ABSORB & 3 & $2.34 \pm 0.52$ & \multirow{3}{*}{0.014} & NA & NA & NA & NA & NA \\
\hline ICROS & 3 & $0.86 \pm 1.42$ & & NA & NA & NA & NA & NA \\
\hline P-value & & 0.400 & & & & & & \\
\hline \multicolumn{9}{|c|}{$\begin{array}{l}\text { Neointimal } \\
\text { volume }\left(\mathrm{mm}^{3}\right)\end{array}$} \\
\hline ABSORB & 3 & $41.32 \pm 22.35$ & \multirow{3}{*}{0.005} & NA & NA & NA & NA & NA \\
\hline ICROS & 3 & $8.08 \pm 12.47$ & & NA & NA & NA & NA & NA \\
\hline P-value & & 0.200 & & & & & & \\
\hline \multicolumn{9}{|c|}{$\begin{array}{l}\text { Neointimal volume } \\
\text { obstruction (\%) }\end{array}$} \\
\hline ABSORB & 3 & $20.67 \pm 2.77$ & \multirow{2}{*}{0.246} & NA & NA & NA & NA & NA \\
\hline ICROS & 3 & $17.46 \pm 28.61$ & & NA & NA & NA & NA & NA \\
\hline $\mathrm{P}$-value & & 0.700 & & & & & & \\
\hline
\end{tabular}

area remained stable over time (baseline, $5.32 \pm 0.89 \mathrm{~mm}^{2}$; 12 months, $4.88 \pm 0.10 \mathrm{~mm}^{2}$; relative change from baseline, $+0.14 \pm 7.95 \% ; P=1.00$; Figure 3D).

Figure 3 shows the regression lines between time and mean lumen area (Figure 4A) or mean device area (Figure 4B) according to 2 time periods (baseline- 1 month and 1-12 months). In this mixed-model linear regression analysis, the rate of decrease (negative slope) in mean lumen area was significantly steeper in the ABSORB group during the first 1 month (estimated mean difference in the slopes, $-1.4 \mathrm{~mm}^{2}$ per month, $95 \% \mathrm{CI}:-2.32$ to $\left.-0.49, \mathrm{P}=0.004\right)$, while there was no significant difference between the groups in the slopes, which were both positive, between 1 and 12 months (estimated mean difference in the slopes, 
(A)

(B)
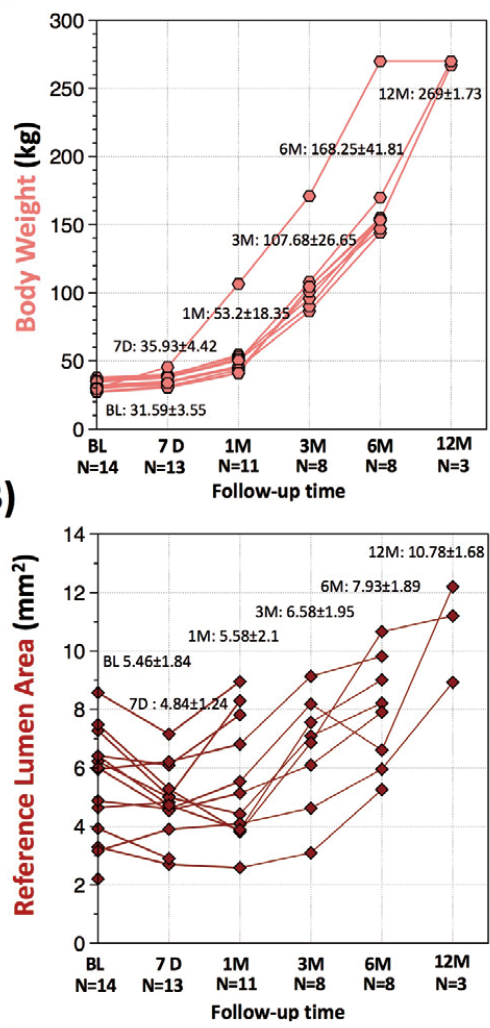

(C)

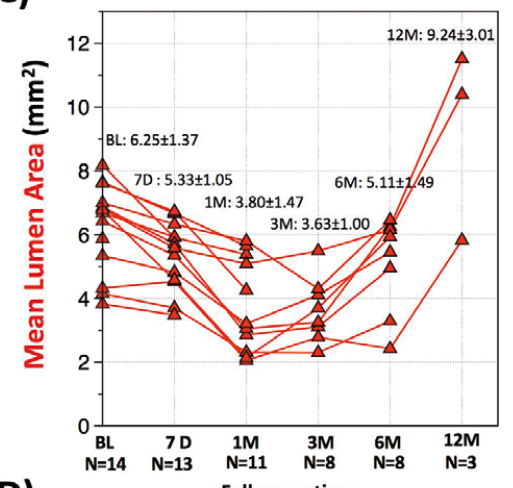

(D)

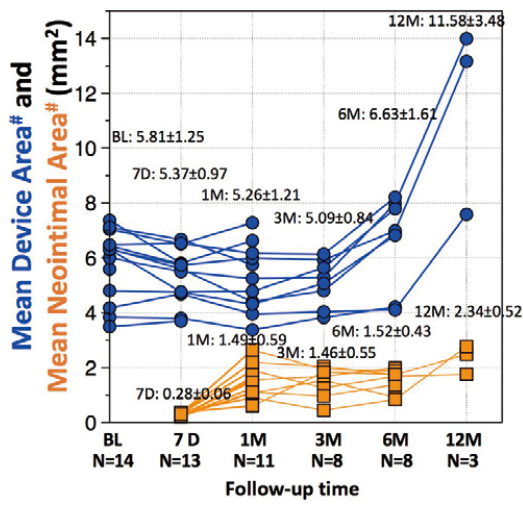

ICROS

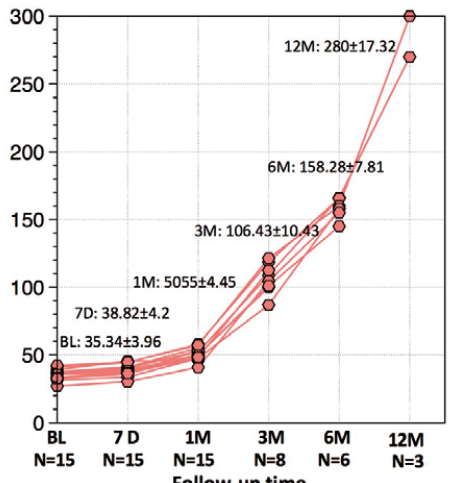

Follow-up time
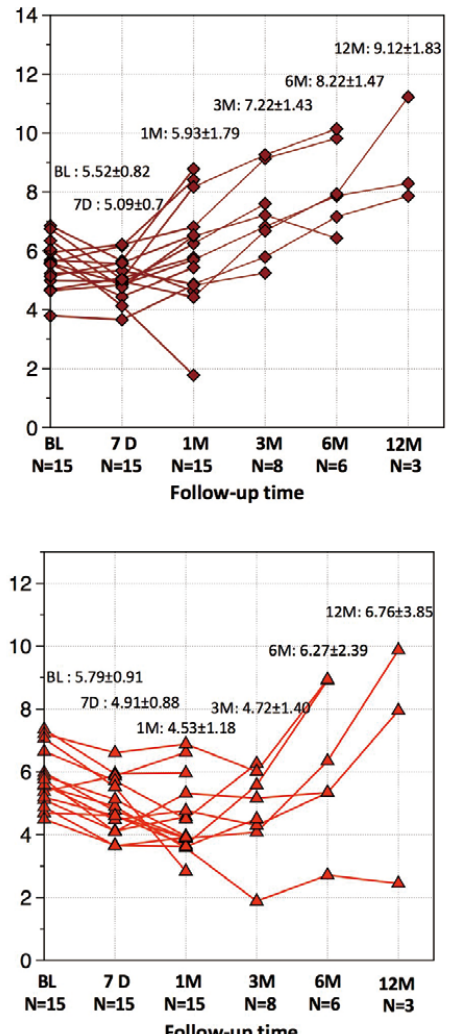

Follow-up time

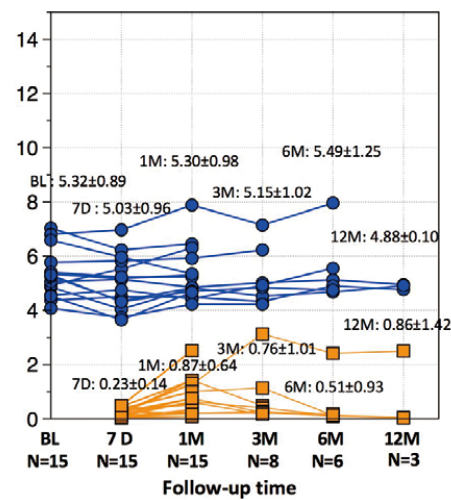

ABSORB vs ICROS
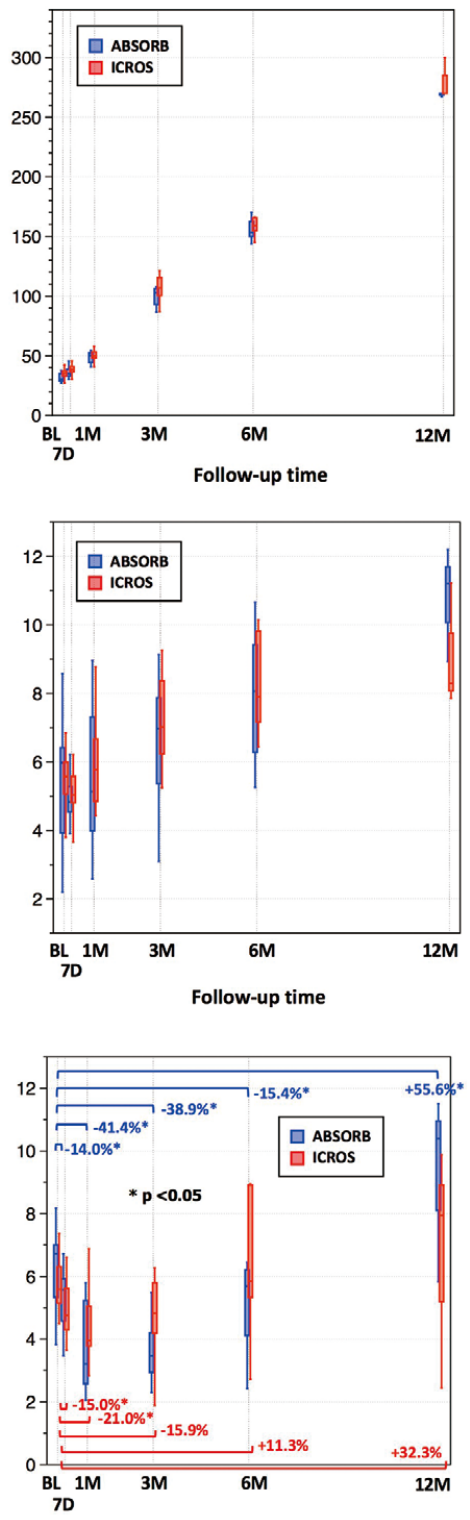

Follow-up time

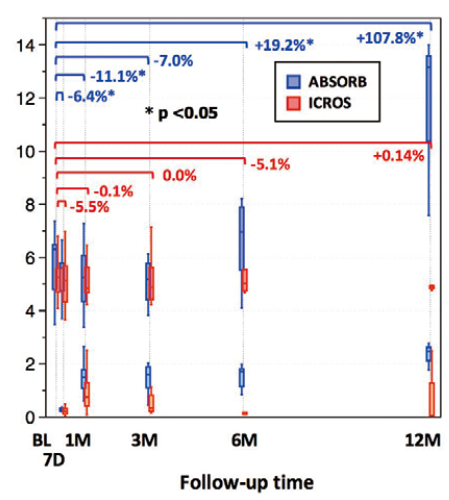

Figure 3. Serial OCT assessments and body weight in the ABSORB and ICROS groups. Individual serial changes in (A) body weight, $(\mathbf{B})$ reference lumen area, $(\mathbf{C})$ mean lumen area, and (D) mean endoluminal scaffold area and mean neointimal area (ontop-of strut). ${ }^{*} \mathrm{P}<0.05$. BL, baseline; $\mathrm{D}$, days; $\mathrm{M}$, month(s); N, no. implanted sites. 


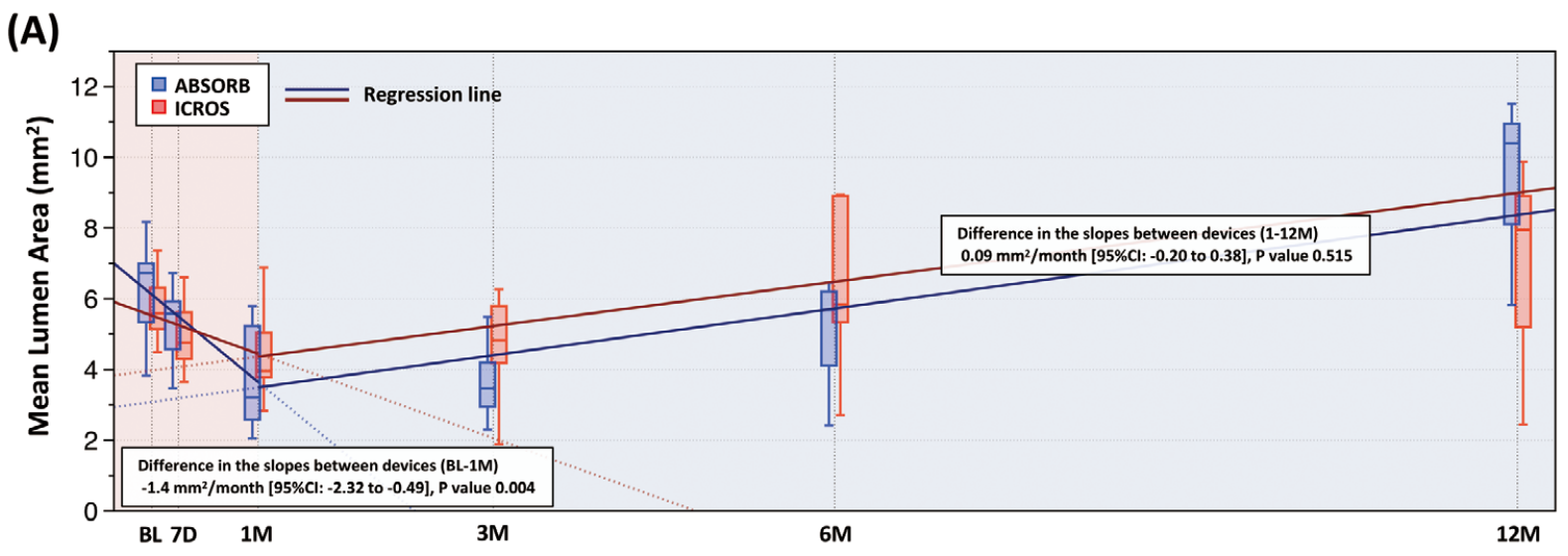

(B)

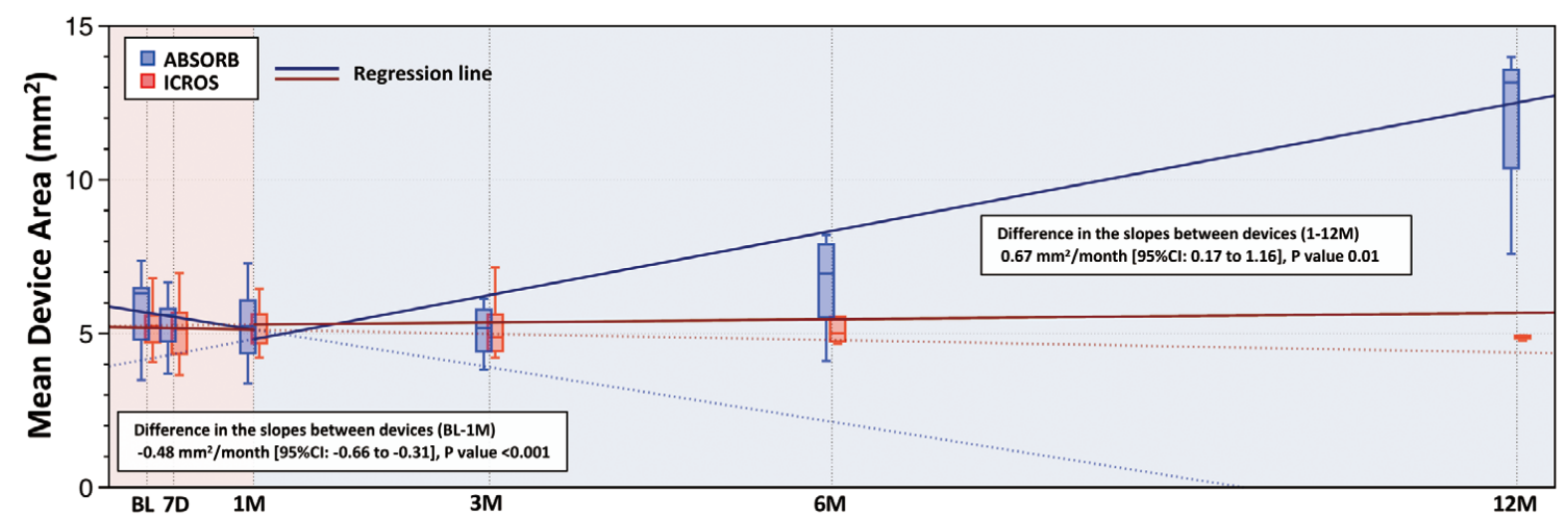

Figure 4. Difference in the rate of area change between ABSORB and ICROS for $(\mathbf{A})$ mean lumen area and (B) mean device area. $\mathrm{BL}$, baseline; $\mathrm{D}$, days; $\mathrm{M}$, month(s).

$0.09 \mathrm{~mm}^{2}$ per month; $95 \% \mathrm{CI}:-0.20$ to $0.38, \mathrm{P}=0.515$; Figure 4A).

Similarly, the rate of decrease (negative slope) in mean device area was significantly steeper in the ABSORB group during the first 1 month (estimated mean difference in the slopes, $-0.48 \mathrm{~mm}^{2}$ per month; $95 \% \mathrm{CI}:-0.66$ to -0.31 , $\mathrm{P}<0.001)$. Device area in the ABSORB group increased while that in the ICROS group remained stable between 1 and 12 months (estimated mean difference in the slopes, $0.67 \mathrm{~mm}^{2}$ per month; $95 \% \mathrm{CI}$ : 0.17 to $1.16, \mathrm{P}=0.01$; Figure 4B).

\section{Histology}

Supplementary Table 3 lists the results of histological analysis. The inflammation scores were increased at 6 and 12 months in both arms ( 1 month, $0.42 \pm 0.38$ in ABSORB vs. $0.39 \pm 0.05$ in ICROS, $\mathrm{P}=0.63 ; 12$ months, $1.11 \pm 0.07$ in ABSORB vs. $0.80 \pm 0.28$ in ICROS, $\mathrm{P}=0.10$ ) whereas the injury scores were stable through 12 months.

\section{Discussion}

The major findings of this serial OCT study in a growing porcine model are as follows: (1) during the first 1 month, lumen area decreased in both the ABSORB and ICROS groups, and the rate of decrease in area was higher in the ABSORB group; (2) during the first 1 month, device area also decreased in the ABSORB group but remained stable in the ICROS group; (3) after the first month, lumen area increased in both groups due to growth of the animal; (4) thereafter, device area increased in the ABSORB group between 3 and 12 months but remained stable in the ICROS group. A schematic representation of the results is given in Supplementary Figure 2.

\section{Early-Phase Luminal Change}

Lumen area reduction was observed in both groups in the early phase (the first 1 month) but the mechanism differed between the 2 groups. In the ICROS group, it appears that neointimal hyperplasia resulting from vessel injury after device implantation was mainly responsible for the lumen reduction, whereas in the ABSORB group, device recoil played an important role in the luminal reduction (Supplementary Figure 2).

The ABSORB BVS has a history of modification of its manufacturing process and strut design to achieve slower degradation and to enhance radial strength for the reduction of acute and late recoil. In the ABSORB Cohort A clinical trial, the first iteration of BVS 1.0 had a relatively high angiographic in-device LLL of $0.44 \mathrm{~mm} 6$ months after implantation. ${ }^{18}$ In that trial, considerable "late recoil", defined as reduction in stent area from after the procedure to the 6-month follow-up, was observed on intravascular 
ultrasound (IVUS; $11.8 \%$ ). Based on these findings, the BVS was modified with improved performance, which was demonstrated in the ABSORB Cohort B clinical trial. In that trial, angiographic in-stent LLL of BVS model 1.1 was $0.19 \mathrm{~mm} 6$ months after implantation, with the elimination of late recoil (relative scaffold area reduction on IVUS, $2.0 \%) .{ }^{19}$ Conversely, in the present animal study, we observed significant scaffold area reduction of the ABSORB BVS 1.1 at 1 month $(11.1 \pm 9.4 \%, \mathrm{P}=0.006)$, which played a major role in the greater luminal area reduction compared with the BMS (Figure 4). This discrepancy may be attributed to the difference in the cellular (smooth muscle cell etc.) and extracellular matrix (collagen contents etc.) reaction to vessel injury after device implantation between humans and the porcine model. ${ }^{20}$ The time frame over which constrictive remodeling develops also seems to differ between swine and human. In the porcine model, constrictive remodeling developed in $\leq 1$ week after balloon angioplasty and peaked at 6 weeks while, in humans, constrictive remodeling progresses between 2 and 6 months after intervention. ${ }^{\mathbf{1 , 2 , 2 1 , 2 2}}$ For future animal experiments for BRS, the differences in the remodeling process between human and animals should be taken into consideration.

Furthermore, in the current study, we observed 1 case of scaffold discontinuity at an early time point (1 month) with a major scaffold area reduction of $38.8 \%$. This might be ascribed to an undetected disruption of scaffold created during the procedure. In that case, a $2.5 \mathrm{~mm}$-sized scaffold was post-dilated by a $3.0-\mathrm{mm}$-sized balloon with a maximum pressure of $8 \mathrm{~atm}$.

\section{Late-Phase Luminal Change}

In the current study, lumen enlargement was observed in both groups in the late phase (3-12 months). Vessel wall expansion has been previously attributed to shear stress or inflammation, although the current study showed the impact of the healthy growth process. In addition to growth, neointimal maturation and regression could have played a role in the ICROS group, a phenomenon explained by the replacement of water-trapping proteoglycans (hyaluronan and versican) by decorin and type I collagen and observed in several BMS studies. ${ }^{23,24}$ In the present study, however, the impact of this phenomenon on luminal enlargement was difficult to evaluate due to the evagination process (Figure 2).

In accordance with swine growth, vessel size gradually increased, as demonstrated by the increase in reference lumen area on OCT $\left(5.46 \pm 1.84 \mathrm{~mm}^{2}\right.$ at post-procedure assessment and $10.78 \pm 1.68 \mathrm{~mm}^{2} 12$ months after implantation). In the present growing animal model, ABSORB showed substantial adaptability to vessel enlargement. Device area in the ABSORB group began to increase following vessel enlargement between 3 months and 6 months after implantation. This resulted in the maintenance of the lumen circularity. Conversely, device area in the ICROS group remained stable over time despite the increasing luminal area. This phenomenon worsened lumen eccentricity due to coronary evagination, which was caused by the outward expansion of the vessel wall despite tethering by the fixed metallic struts hampering outward growth of the lumen (Figure 2, Supplementary Figure 2). ${ }^{25}$

In the current porcine study, scaffold area increased especially between 6 and 12 months following the growth of coronary artery, suggesting that the structural integrity of the device was outperformed by the expansive force of the growth process. In several reports, along with biodegradation, the radial support of $\mathrm{ABSORB}$, which acts to counteract the constrictive force generated by barotrauma of the vessel, begins to decrease 6-12 months after implantation. ${ }^{7,26}$ Likewise, it would be expected that the structural integrity of ABSORB vs. the expansive force of the growth process decreases at the same time. Supplementary Figure 3 shows a representative case with 2-D spread-out maps of ABSORB derived from OCT pullback. ${ }^{27}$ In Supplementary Figure 3, along with the vessel growth, the scaffold was expanded with straightening of the crown of struts at 12 months, although motion artifact by heart beat precluded precise longitudinal assessment. Discontinuation of struts due to scaffold expansion was not clearly identified because the accuracy of the longitudinal assessment was limited.

\section{Current Role of the ABSORB Scaffold and Future Implications}

Despite the fact that the ABSORB scaffold was associated with decreased long-term efficacy and safety compared with current drug-eluting stents, this device can still be used as a benchmark for other devices when it comes to mechanical properties, especially in the early phase. ABSORB 1.1 has been developed to achieve substantial radial force to prevent recoil and constrictive remodeling in humans. ${ }^{19}$ Nevertheless, in the porcine model, considerable scaffold recoil $(11.1 \pm 9.4 \%)$ was observed 1 month after implantation. This extent of recoil in the porcine model may be acceptable for human usage considering the difference in injury response of the vessel after device implantation between human and swine. One should bear in mind this difference for future device experiments in the porcine model.

In the ABSORB II trial, on IVUS 3 years after implantation, expansive vessel wall remodeling was more frequent and intense with the ABSORB BVS than the metallic everolimus-eluting stent. ${ }^{28}$ Assuming that the biodegradation process of ABSORB in the porcine model does not differ from that in humans, the late-phase adaptability of ABSORB observed in the current study may play an important role in the expansive remodeling of human coronary arteries with atherosclerosis.

In the present growing animal model, ABSORB demonstrated substantial growth conformity. In keeping with this observation, a magnesium scaffold (AMS; Biotronik, Bülach, Switzerland) was implanted in the left pulmonary artery of a preterm baby $(1.7 \mathrm{~kg})$ born at 26 weeks of gestation, which achieved left lung reperfusion that persisted throughout the 5-month follow-up period without complications. ${ }^{5}$ And the case of a 3 -year-old child treated with ABSORB was reported with postmortem histology following non-cardiac death 3 months after implantation. On histology, substantial strut coverage with neointima was seen. ${ }^{29}$ Taken together these data suggest that the concept of BRS - full bioresorption after fulfilling the role of scaffolding - is potentially applicable for the treatment of pediatric patients. ${ }^{30}$

It should be noted, however, that the application of BRS technology in pediatric patients will be acceptable once the concerns of long-term safety are eliminated and the applicability for a small vessel is confirmed. On histology in the present study, ABSORB had increased inflammation scores 6 and 12 months after implantation. These results are in line with the report by Otsuka et al in a porcine model. ${ }^{16}$ In that report, the increased inflammation, which 
could cause instability of neointima, was presumably associated with the scaffold degradation process.

\section{Study Limitations}

There are several limitations in the current study. The current study was performed using a non-atherosclerotic porcine model. The potential difference in the biological vascular reactions and the growth rate after device implantation between the current model and human atherosclerotic coronary artery should be considered. The difference in procedural characteristics may influence the present results even though OCT measurements (lumen area, device area etc.) after the procedure were similar between the 2 arms. QCA and OCT analysts could not be blinded to the device type. Biomarker assessment for swine growth using insulin-like growth factor (IGF) or IGF-binding protein 3 was not performed, although somatic growth was obviously observed. ${ }^{31}$

\section{Conclusions}

In a growing porcine model, ABSORB BVS 1.1 was associated with greater recoil 1 month after implantation compared with the ICROS BMS, but demonstrated substantial adaptability to vessel enlargement which began between 3 and 6 months after implantation. The difference in the recoil rate between the porcine model and the human should be taken into account in future animal experiments for new scaffold development. Once the concerns of longterm safety, not related to growth of the subject, are eliminated, the growth capability of the BRS has the potential to be applied to pediatric coronary artery disease.

\section{Disclosures}

A.M. has attended the Advisory Board for Abbott Vascular. J.M. was Coordinator of the European Commission project BIOMAGSCAR. The other authors declare no conflicts of interest.

\section{References}

1. Kimura T, Kaburagi S, Tamura T, Yokoi H, Nakagawa Y, Yokoi $\mathrm{H}$, et al. Remodeling of human coronary arteries undergoing coronary angioplasty or atherectomy. Circulation 1997; 96: $475-483$.

2. Serruys PW, Luijten HE, Beatt KJ, Geuskens R, de Feyter PJ, van den Brand M, et al. Incidence of restenosis after successful coronary angioplasty: A time-related phenomenon. A quantitative angiographic study in 342 consecutive patients at 1,2,3, and 4 months. Circulation 1988; 77: 361-371.

3. Hahn C, Schwartz MA. Mechanotransduction in vascular physiology and atherogenesis. Nat Rev Mol Cell Biol 2009; 10: 53-62.

4. Serruys PW, Onuma Y, Garcia-Garcia HM, Muramatsu T, van Geuns RJ, de Bruyne B, et al. Dynamics of vessel wall changes following the implantation of the absorb everolimus-eluting bioresorbable vascular scaffold: A multi-imaging modality study at 6, 12, 24 and 36 months. EuroIntervention 2014; 9: 1271-1284.

5. Zartner P, Cesnjevar R, Singer H, Weyand M. First successful implantation of a biodegradable metal stent into the left pulmonary artery of a preterm baby. Catheter Cardiovasc Interv 2005; 66: $590-594$

6. Fam JM, Ishibashi Y, Felix C, Zhang BC, Diletti R, van Mieghem N, et al. Conformability in everolimus-eluting bioresorbable scaffolds compared with metal platform coronary stents in long lesions. Int J Cardiovasc Imaging 2017; 33: 1863-1871.

7. Onuma Y, Serruys PW. Bioresorbable scaffold: The advent of a new era in percutaneous coronary and peripheral revascularization? Circulation 2011; 123: 779-797.

8. Nakatani S, Ishibashi Y, Sotomi Y, Perkins L, Eggermont J, Grundeken MJ, et al. Bioresorption and vessel wall integration of a fully bioresorbable polymeric everolimus-eluting scaffold: Optical coherence tomography, intravascular ultrasound, and histological study in a porcine model with 4-year follow-up. JACC Cardiovasc Interv 2016; 9: 838-851.

9. Serruys PW, Chevalier B, Sotomi Y, Cequier A, Carrie D, Piek $\mathrm{JJ}$, et al. Comparison of an everolimus-eluting bioresorbable scaffold with an everolimus-eluting metallic stent for the treatment of coronary artery stenosis (ABSORB II): A 3 year, randomised, controlled, single-blind, multicentre clinical trial. Lancet 2016; 388: 2479-2491.

10. Wykrzykowska JJ, Kraak RP, Hofma SH, van der Schaaf RJ, Arkenbout EK, Ijsselmuiden AJ, et al. Bioresorbable scaffolds versus metallic stents in routine PCI. N Engl J Med 2017; 376: 2319-2328.

11. Yamaji K, Ueki Y, Souteyrand G, Daemen J, Wiebe J, Nef H, et al. Mechanisms of very late bioresorbable scaffold thrombosis: The INVEST Registry. J Am Coll Cardiol 2017; 70: 2330-2344.

12. Ormiston JA, Webber B, Ubod B, Darremont O, Webster MW. An independent bench comparison of two bioresorbable drugeluting coronary scaffolds (Absorb and DESolve) with a durable metallic drug-eluting stent (ML8/Xpedition). EuroIntervention 2015; 11: 60-67.

13. Nakatani S, Sotomi Y, Ishibashi Y, Grundeken MJ, Tateishi H, Tenekecioglu E, et al. Comparative analysis method of permanent metallic stents (XIENCE) and bioresorbable poly-L-lactic (PLLA) scaffolds (Absorb) on optical coherence tomography at baseline and follow-up. EuroIntervention 2016; 12: 1498-1509.

14. Suwannasom P, Sotomi Y, Ishibashi Y, Cavalcante R, Albuquerque FN, Macaya C, et al. The impact of post-procedural asymmetry, expansion, and eccentricity of bioresorbable everolimus-eluting scaffold and metallic everolimus-eluting stent on clinical outcomes in the ABSORB II Trial. JACC Cardiovasc Interv 2016; 9: $1231-1242$.

15. Suwannasom P, Sotomi Y, Asano T, Koon JN, Tateishi H, Zeng $\mathrm{Y}$, et al. Change in lumen eccentricity and asymmetry after treatment with Absorb bioresorbable vascular scaffolds in the ABSORB cohort B trial: A five-year serial optical coherence tomography imaging study. EuroIntervention 2017; 12: e2244e2252.

16. Otsuka F, Pacheco E, Perkins LE, Lane JP, Wang Q, Kamberi $\mathrm{M}$, et al. Long-term safety of an everolimus-eluting bioresorbable vascular scaffold and the cobalt-chromium XIENCE V stent in a porcine coronary artery model. Circ Cardiovasc Interv 2014; 7: $330-342$.

17. Giacino JT, Whyte J, Bagiella E, Kalmar K, Childs N, Khademi A, et al. Placebo-controlled trial of amantadine for severe traumatic brain injury. $N$ Engl J Med 2012; 366: 819-826.

18. Ormiston JA, Serruys PW, Regar E, Dudek D, Thuesen L, Webster MW, et al. A bioabsorbable everolimus-eluting coronary stent system for patients with single de-novo coronary artery lesions (ABSORB): A prospective open-label trial. Lancet 2008; 371: 899-907.

19. Serruys PW, Onuma Y, Ormiston JA, de Bruyne B, Regar E, Dudek D, et al. Evaluation of the second generation of a bioresorbable everolimus drug-eluting vascular scaffold for treatment of de novo coronary artery stenosis: Six-month clinical and imaging outcomes. Circulation 2010; 122: 2301-2312.

20. Schwartz RS, Holmes DR Jr, Topol EJ. The restenosis paradigm revisited: An alternative proposal for cellular mechanisms. $J$ Am Coll Cardiol 1992; 20: 1284-1293.

21. Post MJ, Borst C, Kuntz RE. The relative importance of arterial remodeling compared with intimal hyperplasia in lumen renarrowing after balloon angioplasty. A study in the normal rabbit and the hypercholesterolemic Yucatan micropig. Circulation 1994; 89: 2816-2821.

22. de Smet BJ, Pasterkamp G, van der Helm YJ, Borst C, Post MJ. The relation between de novo atherosclerosis remodeling and angioplasty-induced remodeling in an atherosclerotic Yucatan micropig model. Arterioscler Thromb Vasc Biol 1998; 18: $702-$ 707.

23. Kimura T, Yokoi H, Nakagawa Y, Tamura T, Kaburagi S, Sawada Y, et al. Three-year follow-up after implantation of metallic coronary-artery stents. $N$ Engl J Med 1996; 334: 561-566.

24. Aoki J, Colombo A, Dudek D, Banning AP, Drzewiecki J, Zmudka K, et al. Peristent remodeling and neointimal suppression 2 years after polymer-based, paclitaxel-eluting stent implantation: Insights from serial intravascular ultrasound analysis in the TAXUS II study. Circulation 2005; 112: 3876-3883.

25. Radu MD, Raber L, Kalesan B, Muramatsu T, Kelbaek H, Heo $\mathrm{J}$, et al. Coronary evaginations are associated with positive vessel remodelling and are nearly absent following implantation of newer-generation drug-eluting stents: An optical coherence tomog- 
raphy and intravascular ultrasound study. Eur Heart J 2014; 35: 795-807.

26. Kossuth MB, Perkins LEL, Rapoza RJ. Design principles of bioresorbable polymeric scaffolds. Interv Cardiol Clin 2016; 5: 349-355.

27. Suwannasom P, Onuma Y, Benit E, Gach O, von Birgelen C, Hofma SH, et al. Evaluation of vascular healing of polymer-free sirolimus-eluting stents in native coronary artery stenosis: A serial follow-up at three and six months with optical coherence tomography imaging. EuroIntervention 2016; 12: e574-e583.

28. Serruys PW, Katagiri Y, Sotomi Y, Zeng Y, Chevalier B, van der Schaaf RJ, et al. Arterial remodeling after bioresorbable scaffolds and metallic stents. J Am Coll Cardiol 2017; 70: 60-74.

29. Nazif TM, Kalra S, Ali ZA, Karmpaliotis D, Turner ME, Starc TJ, et al. Percutaneous coronary intervention with bioresorbable scaffolds in a young child. JAMA Cardiol 2017; 2: 430-434.

30. Peters B, Ewert P, Berger F. The role of stents in the treatment of congenital heart disease: Current status and future perspectives. Ann Pediatr Cardiol 2009; 2: 3-23.

31. Slifierz MJ, Friendship R, de Lange CF, Rudar M, Farzan A. An epidemiological investigation into the association between biomarkers and growth performance in nursery pigs. BMC Vet Res 2013; 9: 247.

\section{Supplementary Files}

Please find supplementary file(s); http://dx.doi.org/10.1253/circj.CJ-18-0855 